\title{
DIVULGAÇÃO DE PASSIVOS AMBIENTAIS NO PARÁ: UMA ANÁLISE DAS AUTUAÇÕES DO IBAMA DISCLOSURE OF ENVIRONMENTAL LIABILITIES IN PARÁ: AN ANALYSIS OF IBAMA'S AUTHORATIONS
}

\section{Vanessa Magalhães de Souzal}

\section{Resumo}

Ao desenvolver suas atividades, as entidades que possuem relação com o meio ambiente podem gerar impactos ambientais negativos e em discordância da Lei 9.605/98 de Crimes Ambientais, gerando passivos. A contabilidade é a ferramenta de divulgação das informações contábil-financeiras aos usuários externos, através das demonstrações contábeis. Em se tratando de divulgação de passivos ambientais relacionados a floresta amazônica, destaca-se o Estado do Pará que abriga a floresta amazônica, patrimônio natural da humanidade, e é líder nas autuações aplicadas pelo IBAMA. Diante deste contexto formulou-se o seguinte problema de pesquisa: Como as entidades constituídas como sociedades anônimas autuadas por crimes ambientais no Estado do Pará divulgam em suas demonstrações contábeis esses passivos ambientais? Sendo o objetivo deste estudo verificar se as entidades constituídas como sociedades anônimas autuadas por crimes ambientais incorridos no Estado do Pará divulgam as multas e os processos relacionados a essas autuações em suas demonstrações contábeis. O estudo foi conduzido a partir de pesquisa documental através de técnica de análise de conteúdo, onde foram investigados os dados das demonstrações contábeis contrapondo o relatório de autuações ambientais extraídos do sítio do IBAMA de 9 entidades autuadas no período de janeiro de 2015 a dezembro de 2018. Os resultados mostram que apenas uma empresa da amostra evidencia em balanço e 55,55\% da amostra cita autuações em nota explicativa sem vincular à região afetada.

Palavras-chave: Passivo ambiental. Divulgação. Autuações Ibama. Multa. Pará.

\section{Abstract}

In developing their activities, entities that have a relationship with the environment may generate negative environmental impacts and in disagreement with Law 9605/98 on Environmental Crimes, generating liabilities. On the other hand, accounting is the tool for disclosing accounting-financial information to external users through the financial statements. In the case of disclosure of environmental liabilities related to the Amazon forest, the State of Pará is home to the Amazon forest, a natural patrimony of mankind, and is the leader in the assessments applied by IBAMA. In view of this context, the following research problem was formulated: Howentities constituted as corporations assessed for environmental crimes in the State of Pará disclosing these environmental liabilities in their financial

\footnotetext{
1 Mestranda em Ciências Contábeis pela Fundação Escola de Comércio Álvares Penteado (FECAP), com especialização em Controladoria pela FECAP (2009), São Paulo, São Paulo, Brasil. E-mail: van_magalhaes@yahoo.com.br
} 
statements? The purpose of this study is to verify if entities constituted as corporations assessed for environmental crimes incurred in the State of Pará disclose fines and proceedings related to these assessments in their financial statements. The study was conducted from documentary research through a technique of content analysis, where the data of the financial statements were investigated, as opposed to the report of environmental assessments extracted from the IBAMA website of 9 entities assessed from January 2015 to December 2018 The results show thatonly one company in the sample showing on the balance sheet and 55.55\% of the sample cites notices in an explanatory note without linking to the affected region.

Keywords: Environmental liabilities. Disclosure. Ibama Assessments. Pará.

\section{INTRODUÇÃO}

As atividades econômicas desenvolvidas pelas entidades, pressupõem a interação com o meio ambiente e a utilização de recursos naturais. Considerando que:

\footnotetext{
Dentro desse processo, ao longo dos últimos 50 anos, pode-se afirmar que os recursos naturais são tratados principalmente como insumo para o processo produtivo, especialmente no processo produtivo industrial. Fica evidente que esse modelo, de maneira como foi idealizado e implementado, não se mostra sustentável ao longo do tempo. Existe cada vez mais a consciência de que os recursos naturais são esgotáveis, e, portanto, finitos, se mal utilizados. (TINOCO; KRAEMER, 2004, p. 131).
}

Se a partir desta interação as entidades podem gerar impactos ambientais negativos, por outro lado, a Contabilidade assume o papel de mensurar, reconhecer e divulgar essas externalidades negativas. Sendo o objetivo da divulgação de informações narrar os fatos, trazendo para o leitor uma mensagem que não deixa dúvidas, demonstrando a realidade da empresa e permitindo ao usuário da informação suprir suas necessidades para a tomada de decisão. (PAIVA, 2003).

Apesar disso, a divulgação de informações relativas a externalidades negativas, ou seja, ações da entidade que impõem custos a outros (SLOMSKI; KASSAI; SLOMSKI, 2011) ainda sofre por omissões, passando essas externalidades a serem tratadas como passivo oculto, "cuja informação acerca de sua existência permanece encoberta ao usuário externo dos demonstrativos contábeis e em alguns casos até de seus próprios dirigentes." (PEREIRA; ROCHA; CARDOSO; SILVA, 2001, p. 108). Vale ressaltar que a Contabilidade pode representar uma alternativa para que as entidades que possuem relação direta com a floresta possam manter registradas as consequências que causam ao meio ambiente. (SILVA, 2003).

Dentro deste contexto, realizou-se uma pesquisa sobre as entidades autuadas pelo Instituto Brasileiro do Meio Ambiente e dos Recursos Naturais Renováveis (IBAMA) no Estado do Pará, um dos estados que compõem a Amazônia Legal e que possui o maior valor de autuação ambiental aplicada pelo IBAMA. Tais informações devem ser divulgadas nas demonstrações contábeis em conformidade com o Pronunciamento Técnico 25 (Provisões, Passivos Contingentes e Ativos Contingentes) do Comitê de Pronunciamentos Contábeis (CPC) que estabelece "critérios de reconhecimento e bases de mensuração apropriados a provisões e a passivos e ativos contingentes e que seja divulgada informação suficiente nas notas explicativas para permitir que os usuários entendam a sua natureza, oportunidade e valor." (CPC 25, 2009, p.2). 
Diante do exposto, a pesquisa busca responder a seguinte questão de pesquisa: Como as entidades constituídas como sociedades anônimas que operam no Estado do Pará divulgam em suas demonstrações contábeis os passivos decorrentes de autuações ambientais?

O objetivo geral desta pesquisa consiste em verificar se as entidades constituídas como sociedades anônimas, sejam de capital aberto ou fechado, autuadas por crimes ambientais incorridos no Estado do Pará divulgam as multas e os processos relacionados a essas autuações em suas demonstrações contábeis. Em termos de objetivos específicos, busca-se:

(a) Verificar se no balanço patrimonial existe algum grupo de contas ou uma conta específica que evidencie os passivos ambientais.

(b) Verificar e identificar os termos "autuação", "auto de infração", "crimes ambientais", "crime ambiental”, "Amazônia", "Amazônica" e "IBAMA" nas notas explicativas das respectivas demonstrações contábeis.

Este estudo se justifica pela relevância da divulgação das informações contábeis ao governo, investidores, fornecedores, clientes, credores e sociedade, considerando a busca pela transparência, segurança e confiabilidade que as demonstrações contábeis proporcionam. Iudícibus (1997) afirma que a Contabilidade assume compromisso de evidenciar informações com seus usuários e com os próprios objetivos. As formas de evidenciação podem variar, mas a essência é sempre a mesma: apresentar informação quantitativa e qualitativa de maneira ordenada, de acordo com a relevância e representação fidedigna, a fim de propiciar uma base adequada de informação para o usuário.

Assim, quando há interação da entidade com o meio ambiente, informações relacionadas a externalidades negativas geradoras de passivos ambientais devem ser divulgadas nas demonstrações contábeis seguindo os critérios do CPC 25. Em se tratando de meio ambiente, destaca-se, em especial, a magnitude da Floresta Amazônica para a economia mundial, uma vez que esta provê serviços ecossistêmicos necessários e de grande valor para a prosperidade econômica e perpetuidade da humanidade, ressalta-se ainda que a floresta amazônica é considerada a maior floresta tropical do mundo e concentra um dos mais ricos biomas globais. (JOÃO, 2016). A Amazônia Legal é constituída por nove estados brasileiros: Amazonas, Acre, Amapá, Rondônia, Pará, Roraima, Tocantins, Maranhão (parcial nordeste) e Mato Grosso (parcial centro-oeste).

Diante do exposto, esta pesquisa busca contribuir com novos dados relativos à divulgação de passivos ambientais oriundos de autuações aplicadas pelo IBAMA, corroborando e complementando estudos anteriores, principalmente, no contexto brasileiro.

\section{REFERENCIAL TEÓRICO}

\subsection{Normatização de provisões, passivos e passivos contingentes de acordo com o CPC 25}

O Comitê de Pronunciamentos Contábeis instituído em 2005, e instalado em 2006, tem como função promover a convergência das normas contábeis brasileiras à contabilidade internacional, emitindo procedimentos e normas através dos Pronunciamentos Técnicos (CPC 25, 2009; PETERS, 2011). O CPC 25 provê as definições de provisões, passivo e passivo contingente, sendo provisão um passivo de prazo ou de valor incertos. De acordo com Ribeiro Filho, Lopes \& Pederneiras (2009, p. 109), "o passivo é, usualmente, tratado como obrigações e compromissos de determinada entidade em termos monetários ou na forma de bens ou serviços a terceiros." 
Sendo que a obrigação legal, derivada de contrato, legislação ou outra ação da lei, gerada por eventos passados, faz com que a entidade assuma o compromisso de liquidar essa obrigação (CPC 25, 2009), vale ressaltar que "os administradores e investidores estão interessados nos resultados dos investimentos, considerando que estes sofrem alterações em decorrência de provisionamentos e pagamentos, que podem ser inclusive requeridos por lei." (PETERS, 2011, p. 302).

\footnotetext{
Obrigações decorrentes da relação entre empresa e meio ambiente surgem de várias formas, dentre elas com remediação devido ao não-cumprimento da legislação ambiental vigente ou ainda de problemas de manutenção ou falhas humanas relacionados às etapas de produção, potenciais causadores de acidentes. (PAIVA, 2003, p. 34).
}

Tinoco \& Kraemer (2004, p. 180) acrescentam que "um passivo ambiental deve ser reconhecido quanto existe uma obrigação por parte da empresa que incorreu em um custo ambiental ainda não desembolsado, desde que atenda ao critério de reconhecimento como uma obrigação".

Ainda em relação ao reconhecimento, segundo Gomes, Sampaio, Slomski \& Slomski (2013, p. 30) "a influência dos passivos ambientais nos cálculos do resultado e do valor da empresa tem ganhado importância e reconhecimento no mercado", corroborando com a proposição supracitada de Peters (2011).

Para Ribeiro Filho, Lopes \& Pederneiras (2009, p. 115) "quando um passivo não atende aos critérios necessários para o reconhecimento, é tratado como uma contingência passiva”. Ressalta-se que o passivo contingente é uma obrigação que surge de eventos já incorridos e cuja existência será confirmada de acordo com a ocorrência de eventos futuros, estes que são incertos e que não estão totalmente sob o controle da entidade ou, ainda, uma obrigação atual que surge de eventos passados, que no entanto não é reconhecida dado que é improvável que haja uma saída de recursos contendo benefícios econômicos; ou o valor da obrigação não pode ser mensurado com confiança. (GOMES et al., 2013)

Em consonância com as proposições de Ribeiro Filho Lopes \& Pederneiras (2009) e Gomes et al. (2013), o CPC 25 distingue provisões, que devem ser reconhecidas como passivo dado que é provável uma saída de recursos, de passivos contingentes que não são reconhecidos, tendo em vista que não há uma confirmação de uma obrigação presente e dado que não é provável a saída de recursos.

\subsection{Normatização de divulgação de provisões e passivos contingentes de acordo com o CPC 00}

A contabilidade surgiu com o objetivo de controlar o patrimônio. Tal controle, em sua forma primitiva, era feita através de registros. De acordo com Peters (2011, p. 300) "a contabilidade é de natureza humana e remonta ao princípio de sua civilização". E "a partir da fixação do homem à terra e do surgimento do conceito de propriedade, os indivíduos passaram a utilizar os recursos naturais de acordo com suas necessidades de subsistência." (PAIVA, 2003, p. 9).

No entanto, em consequência das mudanças sociais e econômicas ao longo do tempo, a contabilidade passa a ter um novo enfoque, a partir do despertar de novos usuários que buscam informações através da contabilidade, assim, temas relacionados a divulgação e evidenciação de informações se tornam relevantes. Como é destacado por Peters (2011, p. 300), "é da mensuração, apresentação e evidenciação contábil que se tem a segurança do conhecimento das transações efetuadas e, através de julgamento por parte dos administradores, de estimativas de efeitos de transações futuras."

Tal é a importância da divulgação e evidenciação que estão sendo estabelecidos padrões de relatórios contábeis amplamente conhecidos e aceitos. Em âmbito nacional, foi desenvolvido o CPC 00 (Estrutura Conceitual para Relatório Financeiro) que estabelece os conceitos que fundamentam a 
elaboração e apresentação das demonstrações contábeis, as quais objetivam fornecer informações que sejam úteis na tomada de decisões econômicas e avaliações por parte dos usuários em geral, tais como:

(a) decidir quando comprar, manter ou vender instrumentos patrimoniais;

(b) avaliar a administração da entidade quanto à responsabilidade que lhe tenha sido conferida e quanto à qualidade de seu desempenho e de sua prestação de contas;

(c) avaliar a capacidade de a entidade pagar seus empregados e proporcionar-lhes outros benefícios;

(d) avaliar a segurança quanto à recuperação dos recursos financeiros emprestados à entidade;

(e) determinar políticas tributárias;

(f) determinar a distribuição de lucros e dividendos;

(g) elaborar e usar estatísticas da renda nacional; ou

(h) regulamentar as atividades das entidades.

Vale ressaltar a proposição de Ribeiro Filho Lopes \& Pederneiras (2009, p.267) em que "o termo evidenciação se refere a tornar claro, evidente. Quando utilizamos em contabilidade, significa que estamos divulgando algum tipo de informação e que provocará algum tipo de impacto no usuário".

Em se tratando de divulgação de informações contábeis-financeiras deve-se considerar as características qualitativas fundamentais de relevância e representação fidedigna. De acordo com o CPC 00 (2011) a informação relevante é aquela capaz de fazer diferença nas decisões tomadas pelos usuários e para ser útil, a informação tem que representar um fenômeno relevante com fidedignidade, de forma que a realidade econômica divulgada deve incluir toda a informação necessária para que o usuário compreenda o que está sendo divulgado, incluindo todas as descrições e explicações necessárias, ressalta-se ainda que um retrato da realidade econômica deve estar livre de erros ou omissões. No entanto, conforme afirma Slomski et al. (2011, p.180):

$E$ É importante ressaltar que é pouco provável que a empresa evidencie de forma espontânea a externalidade negativa, dado que ela é sinônimo de passivo ambiental e que pode ser tipificado como crime ambiental passível de aplicação de multas e detenções de seus dirigentes.

De acordo com Xavier \& Luczkiewicz (2013, p. 6):

As pesquisas verificaram que nos relatórios das empresas é muito difícil encontrar as informações de forma quantitativa, o que as empresas divulgam para os usuários são as informações de forma qualitativa. Normalmente as boas e as neutras, dificilmente divulgadas a parte negativa.

\subsection{Estudos anteriores sobre divulgação de passivo ambiental}

Os riscos e oportunidades são percebidos de formas diferentes conforme a relação de dependência das atividades empresariais com o meio ambiente, as entidades podem se beneficiar em maior ou menor escala, assim como pode gerar um impacto ambiental menor ou maior. Dentro deste contexto, e segundo Teixeira \& Ribeiro (2014) os temas mais explorados pelos pesquisadores são evidenciação ambiental, impactos ambientais, performance ambiental e desempenho econômico em relação ao meio ambiente. No que tange a divulgação e evidenciação de passivo ambiental, foram identificadas 7 pesquisas, no período de 2005 a 2018 de âmbito nacional relacionadas ao tema.

Lima \& Garcia (2005) analisaram a forma de mensuração e divulgação dos impactos ambientais na indústria R\&B Plásticos da Amazônia, bem como buscaram identificar de que modo estão sendo 
contabilizados os eventos econômicos relacionados ao meio ambiente. Neste estudo, os autores concluíram que devido à ausência de um controle ambiental na contabilidade, a indústria pesquisada oferece aos seus usuários (internos e externos) poucas informações relativas ao impacto ambiental decorrente de sua atividade.

Em 2006 os pesquisadores Rover, Alves \& Borba (2006) buscaram identificar nas Demonstrações Contábeis Adicionais (Balanço Social e Demonstração do Valor Adicionado) quais eram as diferenças e semelhanças das práticas de evidenciação concernentes aos passivos ambientais entre Brasil e Estados Unidos. Diante os resultados, observou-se que não houve homogeneidade quanto à formatação e apresentação das demonstrações adicionais. Além disso, as informações ambientais publicadas nos EUA são mais amplas do que as publicadas no Brasil.

Xavier \& Luczkiewicz (2013) tinham como objetivo verificar se as empresas do setor de exploração de petróleo com ações listadas na BM\&F BOVESPA evidenciam em seus relatórios financeiros informações acerca de passivos ambientais. Nesta pesquisa foram analisadas 6 empresas do setor petrolífero, e constatou-se que apenas uma empresa evidencia a existência de passivo ambiental no Balanço Patrimonial, enquanto duas evidenciam apenas provisões para contingência em nota explicativa.

No estudo de Cunha \& Ribeiro (2016) em que procederam com uma comparação entre a evolução da divulgação de provisões e passivos contingentes ambientais pelas empresas do setor de energia elétrica com avanços da normatização contábil, identificaram que há uma relação de crescente evidenciação dos passivos ambientais que pode ser um indicativo de que as empresas reagiram aos novos mecanismos regulatórios.

Em estudos mais recentes os pesquisadores observaram as empresas listadas na B3, como segue:

Carvalho, Pimentel \& Oliveira (2018) buscaram descrever como as empresas participantes do Índice de Sustentabilidade Empresarial (ISE) da BM\&F BOVESPA, declararam-se em relação a seus passivos ambientais durante o período de 2012-2015. A partir dos resultados, os autores concluíram que das 67 empresas investigadas, $43 \%$ das empresas que responderam ao questionário nos anos 20122015 declararam não possuir passivos ambientais. Outrossim, apenas 9\% declararam possuir passivos ambientais, provisionaram recursos para o seu saneamento, divulgaram a existência destes passivos nos relatórios pertinentes.

Silva, Araújo \& Santos (2018) analisaram a relação entre a rentabilidade e o disclosure de provisões e passivos contingentes ambientais das empresas de alto potencial poluidor listadas na B3. Os resultados apurados indicaram que as empresas mais rentáveis não são, necessariamente, aquelas que mais divulgam informações sobre provisões e passivos contingentes ambientais.

Formanski, Mendes \& Rover (2018) fizeram uma investigação de quais os fatores que influenciam na divulgação de provisões e passivos contingentes ambientais das companhias listadas na B3 e que foram autuadas pelo Instituto Brasileiro do Meio Ambiente e dos Recursos Naturais Renováveis (IBAMA) entre 2010 a 2016. Diante os resultados, observaram que a divulgação das autuações aplicadas pelo IBAMA, apenas 55,9\% divulgam informações qualitativas e quantitativas nas Demonstrações Financeiras Padronizadas ou nos Relatórios de sustentabilidade.

No âmbito internacional, foram analisados 7 artigos sobre divulgação de informações relacionadas as ações ambientais.

Saida (2009) desenvolveu uma pesquisa em que comparou as informações ambientais divulgadas nos relatórios anuais das empresas multinacionais americanas e europeias. E, também, buscou mostrar os fatores que explicam as diferenças. Os resultados indicaram que as multinacionais europeias revelam mais informações ambientais do que as americanas. Da mesma forma, conclui que a nacionalidade das empresas multinacionais parece ter um efeito no nível da comunicação ambiental. 
Sen, Mukherjee \& Pattanayak (2011) buscaram identificar o estado existente da divulgação ambiental. O estudo mostrou que o nível de divulgação de informações ambientais varia entre setores e empresas, e as informações reveladas nos relatórios anuais são mais qualitativas do que quantitativas.

Os pesquisadores Saraiva, Pires, Gabriel \& Daniel (2015) tinham como principal objetivo analisar as práticas da divulgação das matérias ambientais em organizações cotadas na Bolsa de Valores de Lisboa, durante o período abrangido pelo triênio 2010/2012. Os resultados obtidos demonstram que as empresas portuguesas estão cada vez mais preocupadas com as questões ambientais e a evolução do nível de divulgação ambiental aumentou entre 2010 e 2012, o que mostra a consciencialização desta problemática por parte das entidades.

Os estudos de Khalid, Atkins \& Barone (2016) sugerem que a divulgação de informações sociais, ambientais e éticas permanece uma problemática por causa da má-fé e falta de autenticidade das empresas de mineração que tentam aplacar uma série de partes interessadas. Os autores investigaram por que as empresas ambientalmente sensíveis ainda enfrentam críticas, apesar das extensas divulgações em seus relatórios anuais. Este estudou explorou a extensão das questões sociais, ambientais e éticas específicas nos relatórios das empresas de mineração que operam no país de Gana.

Miralles-Quiros, Miralles-Quiros \& Arraiano (2017) analisaram se a divulgação sobre sustentabilidade fornece informações relevantes e agrega valor aos investidores no cenário europeu, onde essa prática tem aumentado constantemente no período de 2001 a 2013. Os resultados gerais sustentam a crença de que conduzir negócios de acordo com normas éticas é um valor relevante para os investidores europeus. Por outro lado, revelam que não há homogeneidade entre os mercados, mesmo para os períodos anteriores e posteriores à crise financeira global.

Al-Shaer, Salama \& Toms (2017) examinaram os determinantes do volume de divulgações ambientais e sua qualidade, com foco especial no papel dos comitês de auditoria e nos efeitos das recomendações do relatório Smith para o Código de Governança Corporativa do Reino Unido. Empresas com comitês de auditoria (CA) de maior qualidade fazem divulgações de maior qualidade. Empresas maiores com acionistas influentes têm maior volume de divulgações, enquanto a qualidade da CA não impacta no volume de divulgações.

Em estudo mais recente, Passetti, Cinquini \& Tenucci (2018) pesquisaram até que ponto a implementação da gestão ambiental interna e de informações ambientais voluntárias está relacionada à mudança organizacional. Os resultados apontaram a importância de estabelecer principalmente um conjunto de mudanças internas, impulsionadas pelo planejamento ambiental, para promover mudanças organizacionais.

Observando os estudos nacionais encontramos que a maioria aponta para a baixa divulgação de passivo ambiental, enquanto os estudos internacionais indicam a falta de padronização nas informações.

\subsection{A Amazônia Legal e as autuações ambientais aplicadas pelo IBAMA}

A floresta amazônica é considerada a maior floresta tropical do mundo e concentra um dos mais ricos biomas globais e por isso deverá liderar o palco de discussões sobre oportunidades, impactos e riscos ligados à biodiversidade e aos serviços ecossistêmicos para a economia.

A floresta amazônica brasileira também conhecida como Amazônia Legal abrange nove estados brasileiros, são eles: Amazonas, Acre, Amapá, Rondônia, Pará, Roraima, Tocantins, Maranhão (parcial nordeste) e Mato Grosso (parcial centro-oeste), possui uma área aproximada de $5.020 .000 \mathrm{~km}^{2}$ (IBGE, 2015) cuja cobertura florestal corresponde a aproximadamente $12 \%$ da floresta mundial e oferece serviços ecossistêmicos de provisão, regulação, cultural e de suporte os quais são fundamentais para a regulação do clima, equilíbrio ecológico, purificação da água e provisão de matéria-prima. (CONSERVAÇÃO INTERNACIONAL, 2012). 
O desmatamento e a degradação ambiental da floresta amazônica representam um risco para os negócios, sendo impactados pela escassez de recursos, aumento de preços de matéria-prima na cadeia de suprimentos e perda de produtividade. A World Economic Forum em seu relatório "Biodiversity and business risk" (2010) apresenta que de acordo com o '13th Annual Global CEO Survey 2010'conduzido pela PwC, 53\% dos CEO’s da América Latina e 45\% da África estão preocupados com impacto negativo no crescimento de seus negócios devido a perda da biodiversidade.

A relação entre a perda da Biodiversidade e Serviços Ecossistêmicos e a escassez de água envolve dinâmicas ambientais complexas, dificilmente perceptíveis pelos métodos tradicionais de gestão empresarial. Estudos sugerem que a perda dos serviços ecossistêmicos providos pela Floresta Amazônica poderá afetar os principais centros urbanos na região sudeste do País. (CONSERVAÇÃO INTERNACIONAL, 2012)

Corroborando com essa perspectiva foi necessário estabelecer o Instituto Brasileiro do Meio Ambiente e dos Recursos Naturais Renováveis (IBAMA), órgão executivo vinculado ao Ministério do Meio Ambiente que atua em defesa do meio ambiente e regulamenta ações que degradam a natureza através da Lei n. 9.605/98 de crimes ambientais que dispõe sobre as sanções penais e administrativas derivadas de condutas e atividades lesivas ao meio ambiente.

Brito \& Barreto (2006) analisaram em seus estudos a eficácia da aplicação da Lei de Crimes Ambientais analisando 55 processos administrativos referentes a infrações ambientais no Estado do Pará. Da amostra selecionada, $81 \%$ das multas correspondiam a condenados na primeira instância, sendo que apenas $3 \%$ havia pago a multa.

Formanski, Mendes \& Rover (2018) investigaram os fatores que influenciam na divulgação de provisões e passivos contingentes ambientais de 70 companhias listadas na Bolsa de Valores Brasil, Bolsa, Balcão (B3) e que foram autuadas pelo IBAMA. No que tange a divulgação das autuações aplicadas pelo IBAMA, da amostra apenas 55,9\% divulgam informações qualitativas e quantitativas nas Demonstrações Financeiras Padronizadas ou nos Relatórios de Sustentabilidade.

\section{PROCEDIMENTOS METODOLÓGICOS}

A pesquisa tem caráter descritivo pautado em pesquisa documental a partir da técnica de análise de conteúdo, com abordagem qualitativa e análise de frequência e quantitativa, onde são investigados os dados das demonstrações contábeis (Balanço Patrimonial e Notas Explicativas) e o relatório de autuações ambientais extraídos do sítio do IBAMA.

Na pesquisa documental "o propósito a atingir é o armazenamento sob uma forma variável e a facilitação do acesso ao observador, de tal forma que este obtenha o máximo de informação (aspecto quantitativo), com o máximo de pertinência (aspecto qualitativo).” (BARDIN, 2004, p. 40).

O objetivo da análise documental é a representação condensada da informação, para consulta e armazenagem; o da análise de conteúdo é a manipulação de mensagens (conteúdo e expressão), para evidenciar os indicadores que permitam inferir sobre uma outra realidade que não a da mensagem. (BARDIN, 2004, p. 41).

Assim, as análises das notas explicativas têm como objetivo analisar a frequência e quantidade dos termos buscados relacionados às autuações ambientais.

A amostra da pesquisa foi elaborada a partir dos relatórios de autuações ambientais extraídos do sítio do IBAMA referente aos períodos de janeiro de 2015 a dezembro de 2018, selecionando o Estado do Pará. Desses relatórios foram identificadas as entidades constituídas como sociedade 
anônima, totalizando 64 entidades correspondendo a $\mathrm{R}$ \$ 383.570.891,98 em autuações, das quais, de acordo com a materialidade e relevância dos valores de autuação, foram selecionados nove grupos empresariais, totalizando $\mathrm{R} \$ 357.415 .178,20$ em autuações, correspondendo a 93,18\% da população da pesquisa. Entende-se por grupo empresarial as controladoras e suas coligadas.

Tabela 1 - Grupos empresariais selecionados.

\begin{tabular}{|l|r|r|}
\hline Grupos Empresariais & $\begin{array}{c}\text { Quantidade de } \\
\text { autuação }\end{array}$ & $\begin{array}{r}\text { Valor total das } \\
\text { autuações }\end{array}$ \\
\hline Empresa de Energia São Manoel S/A & 3 & 7.920 .500 \\
\hline Jari Florestal S/A & 14 & $12.918 .828,20$ \\
\hline Linhas Xingu Transmissora de Energia S/A & 1 & $15.021 .000,00$ \\
\hline Mineração Rio do Norte S/A & 9 & $17.854 .000,00$ \\
\hline Alunorte Alumina do Norte Brasil S/A & 2 & $20.000 .000,00$ \\
\hline JBS S/A & 32 & $25.020 .000,00$ \\
\hline Norte Energia S/A & 20 & $60.598 .950,00$ \\
\hline Agropecuária Santa Bárbara Xinguara S/A & 16 & $80.670 .100,00$ \\
Vale S/A & 11 & $117.411 .800,00$ \\
\hline Total & 108 & $357.415 .178,20$ \\
\hline
\end{tabular}

Fonte: Adaptado dos relatórios de autuações ambientais do IBAMA

A partir da amostra selecionada, foram extraídas as informações sobre as autuações, assim como os respectivos valores. Ressalta-se que as autuações, cujo campo denominado "status débito" onde constaram como "baixado - defesa deferida" e "quitado - baixa automática", foram eliminadas da amostra, tendo como base a análise de materialidade e relevância dos valores.

Em seguida foram examinadas as demonstrações contábeis (Balanço Patrimonial e Notas Explicativas) dos períodos de 2015 a 2018 para o levantamento, verificação e identificação dos passivos e contingentes ambientais referentes às autuações relacionadas, assim como dos termos "autuação", "auto de infração", "crimes ambientais", "crime ambiental", "Amazônia", "Amazônica" e "IBAMA". Os termos "autuação", "auto de infração", “crimes ambientais", "crime ambiental”, foram selecionados com base na Lei n. 9.605/98 de Crimes Ambientais, o termo "IBAMA" fazendo referência ao órgão competente pela fiscalização e aplicação das multas e os termos "Amazônia" e "Amazônica" fazendo a relação com a Região da Amazônia Legal.

Destaca-se que foi procedida com a análise do período de junho de 2019 dos relatórios de autuações ambientais do IBAMA para verificar possíveis eventos subsequentes que possam ter seu fato gerador em exercícios anteriores e que devem ser divulgados nas demonstrações contábeis.

Considerando que muitas entidades são constituídas com capital fechado, e, portanto, não possuem cadastro na CVM, optou-se por coletar os balanços e as notas explicativas dos sítios dos Diários Oficiais, dos sítios das próprias entidades e do banco de dados da economática, conforme segue: 
Tabela 2 - Banco de dados.

\begin{tabular}{|l|c|c|}
\hline Unidade de Registro & $\begin{array}{c}\text { Balanço } \\
\text { Patrimonial }\end{array}$ & Nota Explicativa \\
\hline Empresa de Energia São Manoel S/A & sítio da entidade & sítio da entidade \\
\hline Jari Florestal S/A & diário oficial & diário oficial \\
\hline Linhas Xingu Transmissora de Energia S/A & economática & diário oficial \\
\hline Mineração Rio do Norte S/A & sítio da entidade & sítio da entidade \\
\hline Alunorte Alumina do Norte Brasil S/A & diário oficial & diário oficial \\
\hline JBS S/A & sítio da entidade & sítio da entidade \\
\hline Norte Energia S/A & diário oficial & diário oficial \\
\hline $\begin{array}{l}\text { Agropecuária Santa Bárbara Xinguara S/A } \\
\text { Vale S/A }\end{array}$ & $\begin{array}{l}\text { diário oficial } \\
\text { economática }\end{array}$ & $\begin{array}{c}\text { diário oficial } \\
\text { sítio da entidade }\end{array}$ \\
\hline
\end{tabular}

Fonte: Elaboração Própria.

A escolha do Estado do Pará decorre do fato de estar inserido na Amazônia Legal, fazendo parte, portanto, da maior extensão de cobertura florestal tropical do Brasil e, conforme os estudos de Brito \& Barreto (2006) que apontam o Estado do Pará como maior produtor de madeira amazônica em 2004, segundo estado com maior área desmatada no mesmo ano e líder de autuações aplicadas pelo IBAMA.

De acordo com o levantamento da presente pesquisa, foi identificado que dentre os estados que compõem a Amazônia Legal, o Estado do Pará segue sendo o líder em autuações aplicadas pelo IBAMA em entidades constituídas como sociedades anônimas no período de janeiro a dezembro de 2018:

Tabela 3 - Autuações IBAMA nos Estados da Amazônia Legal.

\begin{tabular}{|l|r|r|}
\hline & Valor total das autuações & \multicolumn{2}{|c|}{$\%$} \\
\hline Acre & - & $0,00 \%$ \\
\hline Amapá & - & $0,00 \%$ \\
\hline Rondônia & $16.000,00$ & $0,01 \%$ \\
\hline Amazonas & $53.500,00$ & $0,02 \%$ \\
\hline Mato Grosso & $861.600,00$ & $0,39 \%$ \\
\hline Roraima & $2.767 .000,00$ & $1,27 \%$ \\
\hline Tocantins & $6.377 .464,00$ & $2,92 \%$ \\
\hline Maranhão & $29.064 .926,00$ & $13,29 \%$ \\
\hline Pará & $\mathbf{1 7 9 . 5 3 2 . 1 5 7 , 2 8}$ & $\mathbf{8 2 , 1 0 \%}$ \\
\hline TOTAL & $218.672 .647,28$ & $100 \%$ \\
\hline
\end{tabular}

Fonte: Adaptado dos relatórios de autuações ambientais do IBAMA

O método aplicado nesta pesquisa se baseou na análise de conteúdo em que através de técnicas de análise das comunicações, visou obter indicadores que permitam inferências quanto às mensagens. (BARDIN, 2004). Para a análise de dados desta pesquisa tomou-se como diretriz os critérios de divulgação das provisões e passivos contingentes estabelecidos conforme CPC 25. A partir da identificação das entidades autuadas pelo IBAMA, buscou-se a identificação no Balanço Patrimonial de grupo de contas ou conta específica para passivos ambientais, determinando 0 para a não evidenciação e 1 para a evidenciação: 
Quadro 1 - Determinante na identificação da conta passivo ambiental.

\begin{tabular}{|c|c|}
\hline 0 & Não evidencia grupo de contas ou conta específica de passivo ambiental \\
1 & Sim, evidencia grupo de contas ou conta específica de passivo ambiental \\
\hline
\end{tabular}

Fonte: Elaboração Própria.

Quanto a análise das notas explicativas, foi estabelecido como unidade de registro as seguintes palavras: "autuação", "auto de infração", "crimes ambientais", "crime ambiental", "Amazônia", "Amazônica" e "IBAMA", analisando as quantidades de termos e a frequência com que os termos aparecem nas respectivas notas explicativas. De acordo com Gomes (2007), podemos utilizar as palavras como unidade de registro destacadas de acordo com a finalidade do estudo. Além das unidades de registro, numa análise de conteúdo, deve-se compreender o contexto da qual fazem parte as palavras em análise.

Com relação à evidenciação nos eventos subsequentes, foram analisados os relatórios de autuações ambientais do IBAMA no período de janeiro a junho de 2019 e foi observado que nenhum dos grupos empresariais selecionados para esta pesquisa foi autuado, portanto, a investigação de eventos subsequentes se torna dispensável.

\section{ANÁLISE DOS RESULTADOS}

Foram analisadas 9 entidades constituídas como sociedades anônimas, totalizando 108 autuações referentes às infrações relacionadas a cadastro técnico, controle ambiental, biopirataria, crime contra a fauna, crime contra a flora e outras, aplicadas pelo IBAMA no período de janeiro de 2015 a dezembro de 2018 no Estado do Pará. Observou-se, inicialmente, nesta pesquisa que houve uma redução nas autuações ambientais dentro dos setores Madeireiros e Energia Elétrica, enquanto Mineração houve um aumento.

Tabela 4 - Autuações ambientais aplicados pelo IBAMA por setor.

\begin{tabular}{|l|c|c|c|c|c|c|}
\hline Ano & Agropecuária & $\begin{array}{l}\text { Energia } \\
\text { elétrica }\end{array}$ & Madeireira & Mineração & Pecuária & TOTAL \\
\hline 2015 & 105 & 20.310 & 10.384 & 0 & 0 & 30.799 \\
\hline 2016 & 0 & 43.610 & 2.503 & 500 & 0 & 46.613 \\
\hline 2017 & 80.544 & 8.428 & 32 & 0 & 25.020 & 114.024 \\
\hline 2018 & 21 & 11.193 & 0 & 154.765 & 0 & 165.979 \\
TOTAL & 80.670 & 83.541 & 12.919 & 155.265 & 25.020 & 357.415 \\
\hline
\end{tabular}

Fonte: Adaptado dos relatórios de autuações ambientais do IBAMA

Com base nos dados coletados do período analisado de 2015 a 2018 dos balanços patrimoniais das 9 entidades selecionadas, no que se refere a evidenciação de grupo de contas ou conta específica para passivos ambientais, foi constatado que a empresa Norte Energia S/A evidenciou somente em 2018 com a rubrica "provisões socioambientais". Ademais, nenhuma outra entidade apresenta os passivos ambientais segregados dos demais passivos e provisões divulgados nos balanços patrimoniais. Ressalta-se ainda que as demonstrações contábeis da Jari Florestal S/A referente aos exercícios de 2016 a 2018e da Agropecuária Santa Bárbara Xinguara S/A referente ao exercício de 2018 não foram encontradas em nenhuma base pesquisada tais como economática, sítio da entidade e diário oficial.

No que tange as análises de conteúdo das notas explicativas e observando os resultados dispostos na tabela 5, constatou-se a baixa menção das unidades de registros que remetem ao fato das autuações 
ambientais aplicadas pelo IBAMA, as palavras autuação e auto de infração possuem baixa frequência de evidenciação nas notas explicativas, tendo em vista a apuração de 108 multas e autuações que deveriam ser evidenciadas.

Tabela 5 - Resumo da quantidade de unidades de registros analisadas.

\begin{tabular}{|l|c|c|c|c|c|}
\hline Unidade de Registro & 2015 & 2016 & 2017 & 2018 & Total \\
\hline autuação & 2 & 3 & 3 & 3 & 11 \\
\hline auto de infração & 2 & 2 & 5 & 4 & 13 \\
\hline crimes ambientais & 0 & 0 & 0 & 1 & 1 \\
\hline crime ambiental & 0 & 0 & 0 & 0 & 0 \\
\hline Amazônia & 21 & 23 & 24 & 6 & 74 \\
\hline Amazônica & 0 & 0 & 0 & 0 & 0 \\
IBAMA & 9 & 11 & 7 & 12 & 39 \\
\hline
\end{tabular}

Fonte: Dados da pesquisa

Percebe-se que a unidade "Amazônia" é a mais citada nas notas explicativas, com isto verificouse também o contexto em que essa palavra é utilizada, constatando-se que não há nenhum vínculo entre as demais unidades de registro. Em todos os casos tratando-se de nome próprio de controladas, acionistas, banco ou instituição, como segue: Reflorestamento Produtivo Amazônia S.A., Banco da Amazônia, Fundo de Desenvolvimento da Amazônia, Amazônia Energia Participações S.A, Biopalma da Amazônia S.A. e Superintendência de Desenvolvimento da Amazônia.

Figura 1 - Representatividade da frequência das unidades de registro levantadas na pesquisa.

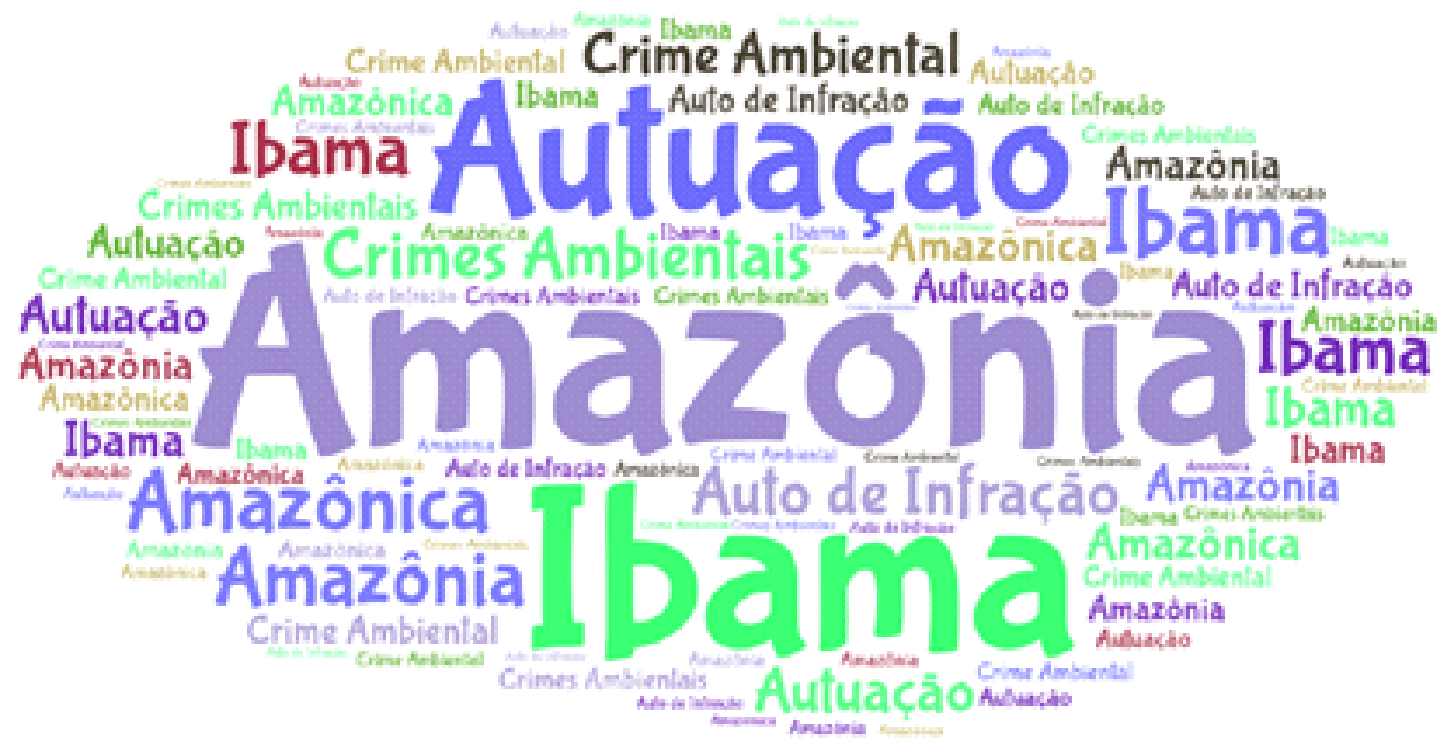

Fonte: Elaboração Própria.

Considerando os resultados encontrados conforme a tabela 4, observou-se as incidências das unidades de registro por grupo empresarial. Para esta observação, foram descartadas as unidades de registro não encontradas nas notas explicativas examinadas, sendo as unidades: "crime ambiental" e "Amazônica"; assim como, também foi descartada a unidade de registro "Amazônia", pela irrelevância do contexto a qual se vincula diante o objetivo da presente pesquisa. Permanecendo para esta observação as unidades de registro: "autuação", "auto de infração", "crimes ambientais" e "IBAMA", conforme apresentado na tabela 6 a seguir: 
Tabela 6 - Unidades de registro por grupo empresarial

\begin{tabular}{|l|c|c|c|c|}
\hline Grupos Empresariais & Autuação & $\begin{array}{l}\text { Auto de } \\
\text { infração }\end{array}$ & $\begin{array}{l}\text { Crimes } \\
\text { ambientais }\end{array}$ & IBAMA \\
\hline Empresa de Energia São Manoel S/A & 0 & 0 & 0 & 1 \\
\hline Jari Florestal S/A & 0 & 0 & 0 & 0 \\
\hline Linhas Xingu Transmissora de Energia S/A & 3 & 0 & 0 & 0 \\
\hline Mineração Rio do Norte S/A & 5 & 4 & 1 & 4 \\
\hline Alunorte Alumina do Norte Brasil S/A & 0 & 0 & 0 & 0 \\
\hline JBS S/A & 0 & 6 & 0 & 8 \\
\hline Norte Energia S/A & 3 & 0 & 0 & 22 \\
\hline Agropecuária Santa Bárbara Xinguara S/A & 0 & 3 & 0 & 3 \\
\hline Vale S/A & 0 & 0 & 0 & 1 \\
\hline
\end{tabular}

Fonte: Dados da pesquisa

De acordo com esse levantamento e considerando a quantidade de autuações e os valores, é possível observar que a Vale S/A, sendo a entidade com o maior valor de autuação aplicado pelo IBAMA, não evidencia as autuações em suas notas explicativas.

Enquanto a Mineração Rio do Norte S/A, que possui um valor total de autuação 6 vezes menor que a Vale S/A, apresenta 14 vezes mais unidades de registros analisadas e evidencia o passivo ambiental em rubrica específica no balanço patrimonial.

Os resultados levantados nesta pesquisa convergem com a conclusão de Elias, Oliveira \& Quintairos (2009), em que em seus estudos analisaram o uso da Contabilidade Ambiental na evidenciação contábil das ações de responsabilidade socioambiental, realizadas pelas empresas do setor de transformação mineral, localizadas no Estado do Pará e os resultados obtidos pelos autores mostram que as empresas estudadas não utilizam as formas de evidenciação contábil para divulgar informações de natureza ambiental de forma segregada. Dificultando para analistas e investidores, realizarem a avaliação de possíveis passivos ambientais futuros, bem como da sustentabilidade organizacional das entidades.

Tendo em vista que esta pesquisa partiu dos relatórios de autuações ambientais do IBAMA, sugere-se que as entidades deveriam divulgar em suas demonstrações contábeis informações sobre esses passivos ambientais em concordância com o CPC 25, no entanto, os resultados confirmam a afirmativa de Slomski et al. (2011) em que é pouco provável que a empresa evidencie de forma espontânea os passivos ambientais relacionados a multas, autuações e crimes ambientais, e convergem com a proposição de Khalid, Atkins \& Barone (2016), onde estudaram os relatórios socioambientais e éticos de empresas de mineração que operam em Gana e os resultados sugerem que as divulgações de informações socioambientais e éticas sofrem uma problemática devido má-fé e falta de autenticidade, o que no âmbito desta pesquisa, corresponde ao não atendimento das características qualitativas fundamentais de relevância e representação fidedigna, conforme menciona o CPC 00.

Cunha \& Ribeiro (2016) estudaram a divulgação de provisões e passivos contingentes ambientais pelas empresas do setor de energia elétrica em comparação ao desenvolvimento da normatização da evidência contábil e se depararam com a assimetria informacional e observaram uma crescente evidenciação dos passivos ambientais, em complemento aos estudos de Cunha \& Ribeiro (2016), esta pesquisa identificou a redução de multas e autuações no setor de energia elétrica.

Vale ressaltar a conclusão de Ferreira et al (2014) que se todas as contingências fossem provisionadas $25 \%$ das empresas estudadas teriam seus lucros reduzidos em mais de $50 \%$ e até mesmo obteriam prejuízos, o que pode justificar a falta de evidenciação, principalmente, no setor de Mineração onde verifica-se um aumento nas multas e autuações. 


\section{CONSIDERAÇÕES FINAIS}

Esta pesquisa buscou responder ao seguinte problema: Como as entidades constituídas como sociedades anônimas que operam no Estado do Pará divulgam em suas demonstrações contábeis os passivos decorrentes de autuações ambientais?

Os resultados levantados nesta pesquisa sugerem que as entidades possuem baixa divulgação de informações sobre obrigações oriundas do descumprimento da Lei de Crime Ambiental, tendo em vista que dos nove grupos empresariais analisados, somente um grupo divulgou em balanço em rubrica específica de passivo ambiental. E cinco grupos empresariais, que perfazem 55,55\% da amostra, fazem menção a autuações em suas notas explicativas, sem, no entanto, vincular essas autuações à região afetada que originou os passivos. Tal informação é relevante pelo fato de se tratar de externalidades negativas, ou seja, afeta a toda a sociedade, e que por outro lado, são passivos passíveis de afetar o resultado, preocupação que cabe principalmente aos investidores, credores e colaboradores, corroborando estudos anteriores.

A partir dos resultados é possível inferir que as entidades tendem a omitir as informações acerca das autuações aplicadas pelo IBAMA, assim como a natureza relacionada a infração, uma vez que não houve uma menção sequer ao fato de essas autuações estarem ligadas a região que abriga a maior floresta tropical do mundo: a Amazônia.

Para pesquisas futuras, sugere-se que sejam levantadas outras autuações ambientais pelas Companhias e Secretarias do Meio Ambiente, a fim de mensurar outros possíveis passivos que não estejam sendo divulgados.

\section{REFERÊNCIAS}

AL-SHAER, H.; SALAMA, A.; TOMS, S. Audit committees and financial reporting quality: Evidence from UK environmental accounting disclosures. Journal of Applied Accounting Research, Melbourne, v.18, n.1, p. 2-21, 2017.

BARDIN, L. Análise de conteúdo. 3.ed. Lisboa: Edições 70, 2004.

BRASIL. Lei n. 9.605, de 12 de fevereiro de 1998. Dispõe sobre as sanções penais e administrativas derivadas de condutas e atividades lesivas ao meio ambiente, e dá outras providências. Disponível em: http://www.planalto.gov.br/ccivil_03/LEIS/L9605.htm. Acesso em: 03 maio 2018.

BRITO, B.; BARRETO, P. A eficácia da aplicação da lei de crimes ambientais pelo Ibama para proteção das florestas no Pará. Revista de Direto Ambiental, São Paulo, v.11, n.43, p. 35-65, 2006.

CARVALHO, M., F.; PIMENTEL, M.S.; BERTINO, R.M.J.; OLIVEIRA, A.R.L. Índice de sustentabilidade empresarial: uma análise acerca da evidenciação do passivo ambiental. Revista Ambiente Contábil, Rio Grande do Norte, v.10, n.1, p. 104-120, 2018.

CONSERVAÇÃO INTERNACIONAL. TEEB para o setor de negócios brasileiro. Relatório preliminar - sumário executivo 2012. Disponível em: http://www.mma.gov.br/publicacoes/ biodiversidade/category/143-economia-dos-ecossistemas-e-da-biodiversidade. Acesso em: 03 maio 2018. 
CUNHA, L. dos S.; RIBEIRO, M. de S. A divulgação de provisões e passivos contingentes ambientais pelas empresas do setor de energia elétrica em comparação ao desenvolvimento da normatização da evidenciação contábil. Revista Universo Contábil, Blumenau, SC, v.12, n.4, p. 86-106, 2016.

ELIAS, L. M. S. L.; OLIVEIRA, E. A. A. Q.; QUINTAIROS, P. C. R. Responsabilidade ambiental: um estudo sobre o uso da evidenciação contábil pelas indústrias de transformação mineral do Estado do Pará. Revista Brasileira de Gestão e Desenvolvimento Regional, Taubaté, SP, v.5, n.3, p. 204-220, 2009.

FERREIRA, D. D. M.; BORBA, J. A.; ROSA, C. A.; VICENTE, E. F. R. Relevância das contingências ambientais: uma investigação nas empresas brasileiras. Contabilidad y Negocios, Lima, v.1, n.9, p. 58-74, 2014.

FORMANSKI, G. C.; MENDES, V. G.; ROVER, S. Provisões e passivos contingentes ambientais: uma análise dos fatores que influenciam a divulgação das companhias listadas na B3 e autuadas pelo Ibama entre 2010 a 2016. In: XII CONGRESSO ANPCONT, João Pessoa, PB, 2018.

GOMES, R. Análise e interpretação de dados de pesquisa qualitativa. In: MINAYO, M.C.S. (org.). Pesquisa social. 26.ed. Petrópolis, RJ: Vozes, 2007. cap.4, p.79-106.

GOMES, S. M. da S.; SAMPAIO, M. S.; SLOMSKI, V.; SLOMSKI V. G. Compreendendo a Controladoria Ambiental. In: GOMES, S. M. da S.; GARCIA, C. O. (orgs.). Controladoria ambiental: gestão social, análise e controle. São Paulo: Atlas, 2013.p. 23-42.

\section{INSTITUTO BRASILEIRO DE GEOGRAFIA E ESTATÍSTICA- IBGE. Indicadores de} desenvolvimento sustentável. Rio de Janeiro: IBGE, 2015.

\section{INSTITUTO BRASILEIRO DO MEIO AMBIENTE E DOS RECURSOS NATURAIS} RENOVÁVEIS - IBAMA. 2017. Consulta a embargos e auto de infração. Disponível em: https:// servicos.ibama.gov.br/ctf/publico/areasembargadas/ConsultaPublicaAreasEmbargadas.php. Acesso em: 19 out. 2018.

IUDÍCIBUS, S. Teoria da contabilidade. 5.ed. São Paulo: Atlas,1997.

JOÃO, C.M. Áreas protegidas da Amazônia: um estudo das contribuições da Natura e O Boticário. 2016. Disponível em: https://www.usp.br/mudarfuturo/cms/?p=693. Acesso em: 26 abr. 2018.

KHALID, S.M.; ATKINS, J.; BARONE, E. Sartrean bad-faith? Site-specific social, ethical and environmental disclosures by multinational mining companies. Accounting, Auditing \& Accountability Journal, Melbourne, p.1-26, 2016.

LIMA, M.S.; GARCIA, A.S. Mensuração e divulgação dos impactos ambientais na indústria: o caso R\&B Plásticos da Amazônia. Revista Universo Contábil, Blumenau, SC, v.1. n.2, p.72-85, 2005. 
MIRALLES-QUIROS, M. M.; MIRALLES-QUIROS, J. L.; ARRAIANO, I. G. (2017) Are Firms that Contribute to Sustainable Development Valued by Investors?. Corporate Social Responsibility and Environmental Management, v.24, p.71-84, 2017.

PAIVA, P. R. Contabilidade ambiental: evidenciação dos gastos ambientais com transparências e focada na prevenção. São Paulo: Atlas, 2003.

PASSETTI, Emílio; CINQUINI, Lino; TENUCCI, Andrea. Implementing internal environmental management and voluntary environmental disclosure: does organisational change happen.

Accounting, Auditing \& Accountability Journal, Melbourne, v.31, n.4, p.1145-1173, 2018.

PEREIRA, A.C.; ROCHA, J.B. da; CARDOSO JR, J.F.; SILVA, J.C. A relevância do passivo oculto no "Disclosure" da informação contábil. Revista Álvares Penteado, São Paulo, v.3, n.6, p. 107$118,2001$.

PETERS, M. R. S. Contribuição da contabilidade gerencial à contabilidade societária. In: PARISI, C.; MEGLIORINI, E. (orgs.). Contabilidade gerencial. São Paulo: Atlas, 2011.p.-298-312.

PRONUNCIAMENTO técnico CPC 25, de 16 de setembro de 2009. Provisões, Passivos Contingentes e Ativos Contingentes. Disponível em: http://static.cpc.aatb.com.br/Documentos/304_ CPC_25_rev\%2012.pdf. Acesso em: 02 nov. 2018.

PRONUNCIAMENTO técnico CPC 00, de 2 de dezembro de 2011. Estrutura Conceitual para Elaboração e Divulgação de Relatório Contábil-Financeiro. Disponível em: http://static.cpc.aatb. com.br/Documentos/147_CPC00_R1.pdf. Acesso em: 02 nov. 2018.

RIBEIRO FILHO, J. F.; LOPES, J.; PERDENEIRAS, M. M. M. (orgs.). Estudando teoria da contabilidade. São Paulo: Atlas,2009.

ROVER, S.; BORBA, J.A. A evidenciação das informações ambientais nas demonstrações contábeis das empresas que atuam no Brasil e que negociam ADRs na Bolsa de Valores dos Estados Unidos: uma análise das DFP's (CVM) e do relatório 20-F (SEC). 2014.

ROVER, S.; ALVES, J.L.; BORBA, J.A. A evidenciação do passivo ambiental: quantificando o desconhecido. Revista Contemporânea de Contabilidade, Florianópolis, SC, v.1, n.5, p. 41-58, 2006.

SAIDA, D. Contribution on the analysis of the environmental disclosure: a comparative study of American and European multinationals. Social Responsibility Journal, Melbourne, v.5, n.1, p.8393, 2009.

SARAIVA, H.I.B.; PIRES, A.S.R.; GABRIEL, V.M.S.; DANIEL, A.C.M. A Contabilidade ambiental e as práticas de divulgação de informação ambiental em Portugal. In: XV CONGRESSO INTERNACIONAL CONTABILIDADE E AUDITORIA, Coimbra, Portugal, 2015. 
SEN, M.; MUKHERJEE, K.; ATTANAYAK, J. K. Corporate environmental disclosure practices in India. Journal of Applied Accounting Research, v.12, n.2, p.139-156, 2011.

SILVA, A. F. P.; ARAÚJO, R. A. M.; SANTOS, L. M. S. Relação da rentabilidade e o disclosure de provisões e passivos contingentes ambientais das empresas de alto potencial poluidor listadas na B3. In: XII CONGRESSO ANPCONT, João Pessoa, PB, 2018.

SILVA, E. L. Uma contribuição da contabilidade ao acompanhamento das atividades do setor madeireiro na Amazônia Paraense. Dissertação (Mestrado em Controladoria e Contabilidade) Faculdade de Economia, Administração e Contabilidade, Universidade de São Paulo, São Paulo: USP, 2003.

SLOMSKI, V.; KASSAI, J. R.; SLOMSKI V. G. Contabilidade gerencial e sustentabilidade. In: PARISI, C.; MEGLIORINI, E. (orgs.). Contabilidade gerencial. São Paulo: Atlas, 2011.p. 314330.

TEIXEIRA, L. M. S.; RIBEIRO, M. S. Estudo bibliométrico sobre as características da contabilidade ambiental em periódicos nacionais e internacionais. Revista de Gestão Social e Ambiental, São Paulo, v.8, n.1, p. 20-36, 2014.

TINOCO, J. E. P.; KRAEMER, M. E. P. Contabilidade e gestão ambiental. São Paulo: Atlas, 2004.

WORLD Economic Forum, \& PricewaterhouseCoopers - PwC. Biodiversity and business risk: A Global Risks Network briefing. World Economic Forum, Genebra, Suíça. 2010. Disponível em: https://www.pwc.co.uk/assets/pdf/wef-biodiversity-and-business-risk.pdf. Acesso em: 20 jul. 2018.

XAVIER, V.V.N.T.; LUCZKIEWICZ, D.A. Passivo ambiental e sua evidenciação nas empresas do segmento de petróleo. In: XX CONGRESSO BRASILEIRO DE CUSTOS, Uberlândia, MG, 2013. 